\title{
XLIII. A. New form of platinum resistance- thermometer, specially adapted for the continuous-flow calorimeter
}

\author{
H.T. Barnes D.Sc. \& D. Molntosh M.A.
}

To cite this article: H.T. Barnes D.Sc. \& D. Molntosh M.A. (1903) XLIII. A. New form of platinum resistance-thermometer, specially adapted for the continuous-flow calorimeter, Philosophical Magazine Series 6, 6:33, 350-352, DOI: 10.1080/14786440309463026

To link to this article: http://dx.doi.org/10.1080/14786440309463026

冓 Published online: 15 Apr 2009.

Submit your article to this journal ¿

Џll Article views: 2

Q View related articles ¿ 
potential-differences for the different pairs of metals are as follows:-

\section{Difference of Potential.}

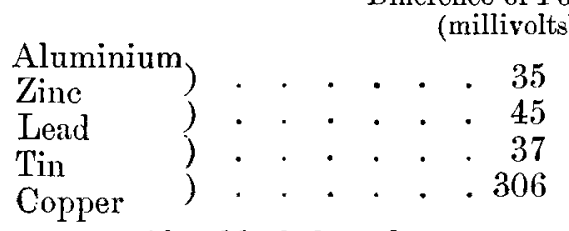

values which are considerably below those generally adopted.

\section{Conchusions.}

The gas between the two cylinders always contains a number of ions, and, on account of the greater rate of diffusion of the negative ions, it is possible that an excess of these would impinge upon the inner cylinder in a given time, and thus leave it negatively charged. The resulting potential, however, should be the same for all metals on this hypothesis.

Again, it is possible that the very penetrating radiation which is present in ordinary air may consist of negatively charged matter, and that the negative charge taken up by the inner cylinder represents the amount of this radiation intercepted by it. But the high value obtained for aluminium, together with the results obtained with Röntgen rays, is against this conclusion.

It seems rather that a process is going on at the surface of the metal, whereby an excess of positively charged corpuscles is being continually emitted, and that the steady state attained represents a condition of equilibrium in which the current between the cylinders is equal to the rate of efflux of the positive charges.

XLIII. A New Form of Platinum Resistance-Thermometer, specially adapted for the Continuous-flow Calorimeter. By H. T. Barnes, D.Sc., Assistant Professor of Physics, and D. MoIntosn, M.A., Demonstrator in Chemistry, Mc Gill University*.

NE of the difficulties to be overcome in constructing a sensitive platinum thermometer is to restrict the size of the coil of wire forming the bulb. In order to bave a sufficient length of wire it is often necessary to make the bulb inconveniently large, and thereby sacrifice quickness of register.

The form of thermometer which we have devised meets this difficulty to a considerable extent, and has enabled us to use shorter bulbs.

$$
\text { * Communicated by Prof. H. L. Callendar, F.R.S. }
$$


The main point about the thermometer is that a core passes through the centre of the bulb, through which a liquid or gas can be made to flow. It is therefore particularly well adapted for the continuous-flow calorimeter, where the temperature of a flowing liquid or gas is measured. It is quite as easy to construct as the mica-frame type, and it has many advantages over the latter for the particular use for which it was designed, although it would be unsuited for certain types of temperature measurement.

To construct the thermometer, a glass tube about $5 \mathrm{mms}$. in diameter and $25 \mathrm{cms}$. long is coated by beeswax for a considerable length, and a thread is cut in the wax on a machinelathe. By means of hydrofluoric acid the glass is etched away, and a permanent thread is produced on the tube. When the wax is removed a point of glass is raised on the tube by means of a blowpipe, leaving a margin of about half a centimetre from the end. The platinum wire is wound on double in the usual way, the point of glass preventing the wire from slipping. The two ends of the coil are fastened down to the glass after winding by points of hot glass, leaving at least $1 \mathrm{~cm}$. free at the ends.

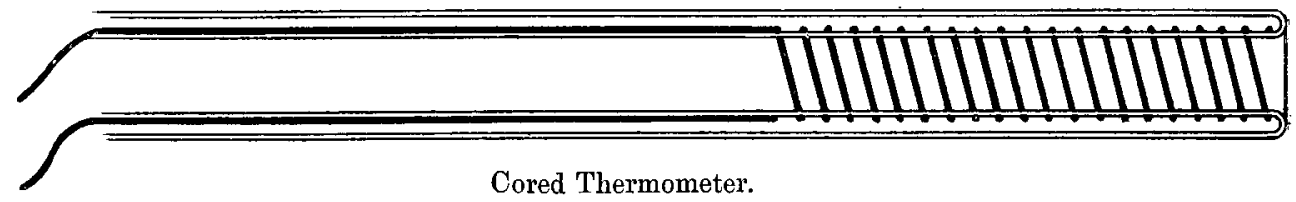

These free ends are fused to silk-covered copper wires of about No. 24 gauge in the blowpipe, which serve as connecting-leads. The copper wires must be longer than the glass tube, and are fastened securely to the tube in two places by binding-thread. The compensating leads of copper wire, connected by a short piece of platinum wire, are bound in the same way to the tube, and the platinum wire caught on a point of hot glass. The length of this platinum connecting wire will depend on the length of wire in the bulb. Usually it varies from $1 \mathrm{~cm}$. to $3 \mathrm{cms}$. Besides being a convenient way of joining the compensating leads together at the bulb, the short bit of wire serves, as suggested by Callendar, the purpose of compensating for the conduction of heat away from the wire by the leads. As soon as the wires are fastened in place the points of glass are made as flat as possible by means of a small blowpipe-flame. A thin glass tube is then selected, which just slides over the bulb and connecting wires. The two tubes are carefully fused together around the end so as not to melt the glass near the wire. At 
the other end the two tubes are of unequal length, with the inner projecting several centimetres beyond the outer. The copper leads are bent over the outer tube and bound securely. The two tuhes are closed at this point by shellac or marine glue, or, where temperatures higher than that of boiling water are to be measured, the space may be closed by binding around a rubber strip.

The length and diameter of the bulb will depend on the fineness of the thread and of the wire, and on the length of wire required to give the requisite resistance. As a rule, 6-mil wire is suitable for most thermometers; but we have used 4-mil wire with very satisfactory results. The thermometer has a small heat capacity, and as the liquid passes through the centre of the bulb as well as over the outside, it is exceedingly quick reading.

It is particularly suited for measuring steam-points. When it is placed in a hypsometer the steam passes out throngh the thermometer and keeps the entire length of stem at the steam temperature. It has been shown by one of us * that the length of stem exposed at the high temperature is an important consideration for very accurate measurement. The use of copper wire as leads, which is much to be recommended, has one disadvantage in having a high conducting-power for heat. With the mica-frame thermometer, unless a great length of stem is immersed in the steam-jacket, the conduction of heat from the air-space around the bulb by the leads produces a small error.

With the cored thermometer no such stem-correction is needed, since the leads are heated for their entire length by the flowing steam.

In taking an ice-point the water around the ice in which the bulb is immersed is drawn up through the thermometer and discharged again into the mixture. This can be easily arranged with a small laboratory water-pump.

The sulphur-point is more difficult to obtain; but, as a rule, for accurate temperature measurement it is not necessary to go as high as that. If it is desired to determine the constant of the wire, where this is not known, a mica-frame thermometer should be tested which has been made from a piece of the same sample of wire. Temperature measurements by the platinum thermometer are now so universal that it is easy to obtain the pure wire with known constants.

We have tested a number of these cored thermometers of different resistances, and find them exceedingly quick and accurate.

IfcGill University, June, 1903.

* Phil. Trans. vol. cxcix. p. 195 (1902). 